\title{
PROPOSIÇÃO DE UM MODELO EXPERIMENTAL DE CADEIA DE VALOR NO SETOR PÚBLICO EM ATENDIMENTO ÀS NECESSIDADES DO CIDADÃO
}

\author{
Marília Cristina Sassim Jesus, Ulisses Sampaio Soares, Valéria Brito de Sousa, \\ Stela Gomes Faiad, Deborah Virgínia Macedo Arôxa e Carlos Eduardo Lacerda Veiga \\ Universidade de Brasília - Departamento de Engenharia Elétrica, Brasília - DF, Brasil - Zipcode 70910-900
}

\begin{abstract}
RESUMO
O presente artigo tem como objetivo apresentar os resultados de um estudo experimental realizado no setor público, o que possibilitou a elaboração de um modelo de Cadeia de Valor. Tal modelo tem como intuito suprir as necessidades de adequação conceitual à realidade do setor público. Nesse sentido, o modelo apresenta seis blocos de informação dispostos em um diagrama, contendo os processos e macroprocessos de acordo com a execução do negócio, além dos seguintes elementos organizacionais: estratégia, processos e estrutura organizacional. Nessa pespectiva, os proveitos inerentes à utilização do modelo de Cadeia de Valor customizado buscam garantir a representatividade, dos elementos organizacionais de uma instituição pública em um só modelo, promovendo o auto-conhecimento da organização, a partir da visão global de seus elementos organizacionais, assim, possibilitando melhorias e aprimoramentos voltados para as necessidades do cidadão.
\end{abstract}

PALAVRAS-CHAVE

Inovação, Setor Público, Cadeia de Valor

\section{INTRODUÇÃO}

O mundo e, especialmente, as burocracias do setor público vem sofrendo transformações ao depararem-se com os novos anseios da sociedade. Sob essa ótica de gestão, a inovação é fundamental, uma vez que ela traz a vantagem competitiva para as organizações. Diante de um ambiente de constantes mudanças e inovações, as organizações precisam definir suas estratégias com o intuito de inserir a inovação em um cenário de diferencial competitivo e diversificação.

Para o presente trabalho, será considerado o conceito de inovação organizacional adotado por Lopes (2009) que diz que as inovações são implementações de práticas, métodos, técnicas de gestão, processos e formas de organização do trabalho.

Diante deste contexto, o presente artigo propõe um modelo experimental de Cadeia de Valor para o setor público, com abrangência holística da organização. O modelo proposto tem como objetivo garantir uma customização que atenda ao negócio público.

O artigo está organizado de forma a apresentar inicialmente uma análise sucinta sobre a literatura existente. Em seguida, será apresentada a metodologia utilizada e a proposição de modelo experimental esquemático de Cadeia de Valor. Por último serão apresentados as considerações finais e os agradecimentos, bem como o referencial bibliográfico.

\section{REVISÃO BIBLIOGRÁFICA}

Baldam (2014) define Cadeia de Valor como um instrumento que analisa as vantagens competitivas da empresa. Tal conceito surgiu em meados dos anos 70, onde o termo Cadeia de Valor começou a ser utilizado a partir do relacionamento dos elementos de custo e valor, adotados por práticas de análise de valor introduzidos por Miles (1947). Mais tarde, nos anos 80, Porter (1990) considerou que a Cadeia de Valor é um sistema de 
atividades interdependentes conectadas por elos, enquadrando as atividades de valor da empresa em categorias, distribuídas em:

i. Atividades primárias: são as relacionadas com a criação ou transformação dos produtos e serviços para o cliente final da organização.

ii. Atividades de apoio ou suporte: são as que apoiam, direta ou indiretamente, a execução das atividades primárias.

Gonçalves (2000) categoriza processos de negócios por três tipos: processos de negócio, que caracterizam a atuação da empresa, processos organizacionais, que viabilizam o funcionamento coordenado de vários subsistemas de apoio da organização, e processos gerenciais, que incluem ações de medição e ajuste do desempenho da organização.

Para fins do presente estudo e elaboração do modelo experimental, será adotado os conceitos de Baldam (2014).

\section{METODOLOGIA}

Com o objetivo de aprofundar o conhecimento acerca da temática e melhor desenvolvimento da proposta de modelo, optou-se pela realização de um estudo qualitativo de natureza descritiva, que foi viabilizado por meio da coleta de dados a partir de pesquisas bibliográficas e entrevistas semiestruturadas. Após a revisão da literatura, observou-se a necessidade de consolidação de um modelo único, em que os agentes públicos conseguissem identificar o seu tipo de negócio, bem como o seu desdobramento, somado à estratégia de cada organização pública. A coleta de informações deu-se pela técnica de entrevista semiestruturada, tendo como objetivo a elaboração de um modelo que refletisse a natureza do setor público e que agregasse valor para o cidadão.

Segundo Minayo (1992), a entrevista semiestruturada pode ser definida como uma técnica reveladora de condições estruturais de sistemas, normas, símbolos e valores, uma vez que pressupõe um diálogo entre entrevistado e entrevistador com ênfase nos objetivos preestabelecidos. Nesse caso, adotou-se perguntas que enfatizassem as necessidades do cidadão, os pontos de alerta revelados por seus discursos, além de necessidades não atendidas ou, até então, não identificadas. Além disso, levou-se em conta o diagnóstico prévio organizacional, a partir de um projeto com duração de dezoito meses, realizado em um órgão público da Administração Direta, que interfaceia como órgão gestor com diversos órgãos que oferecem serviços e políticas públicas ao cidadão, também chamados como órgãos setoriais. Como resultado, obteve-se um diagnóstico da situação atual, o qual possibilitou a ideação do modelo sugerido nesse trabalho.

\section{MODELO PROPOSTO}

O modelo experimental de Cadeia de Valor proposto, visa compilar em um único modelo, elementos que demonstrem a integração de informações relevantes entre os direcionadores estratégicos, os processos de negócios, além das informações referentes à estrutura organizacional do órgão analisado.

Conforme exposto no diagrama na Figura 1, o modelo experimental proposto neste estudo é formado por seis blocos de informações, sendo que esse quantitativo não é euxarível e foi determinado conforme a missão do órgão escolhido. Tais blocos contêm os respectivos macroprocessos e os processos dispostos de forma encadeada, de acordo com a perspectiva de execução do negócio, respeitando a entrada, consumo e saída de informações. 


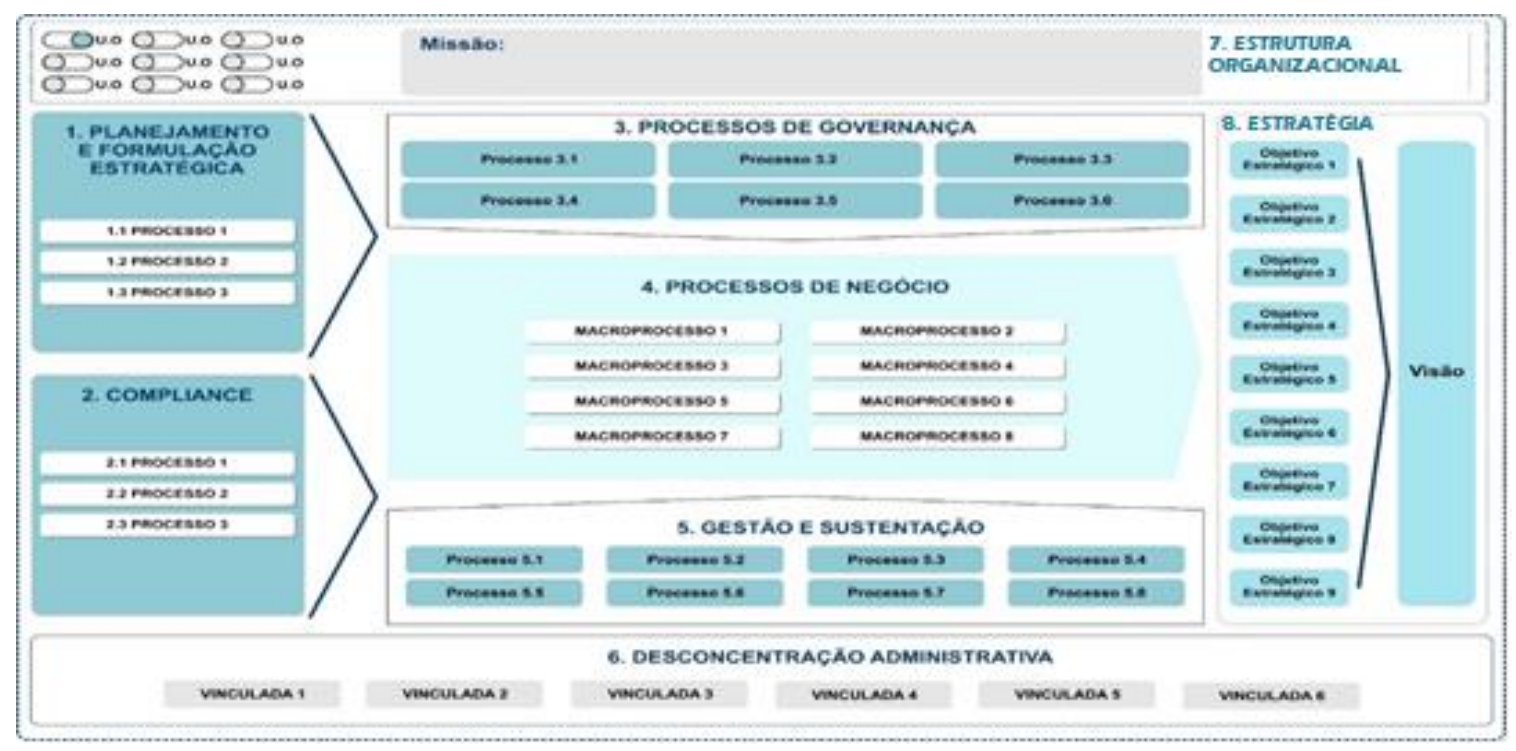

Figura 1. Modelo experimental da Cadeia de Valor

Os blocos de informação e macroprocessos, possuem as seguintes características, conforme a Figura 1:

- Bloco de macroprocessos de planejamento e formulação estratégica (1): são macroprocessos orientados a uma visão ponta a ponta do negócio e agrupados por seu valor estratégico na criação e apoio ao negócio. Foram separados propositalmente, dada a complexidade do negócio público e a urgência na coordenação e planejamento para com as partes interessadas e demais órgãos vinculados. Para esse modelo, foi enfatizado, dado o negócio do órgão utilizado.

- Bloco de macroprocessos compliance (2): mostra os macroprocessos que garantem a conformidade e aderência dos procedimentos internos e externos. Foi destacado propositalmente por conta da exigência da sociedade em manter o negócio público transparente e controlado, o que agrega alto valor e impacto na missão e visão do órgão;

- Bloco de macroprocessos de governança (3): macroprocessos estratégicos ou de gerenciamento, utilizados para medir, monitorar, controlar atividades e administrar o presente e o futuro do negócio;

- Bloco de macroprocessos de negócio (4): macroprocessos finalísticos ou primários, tipicamente interfuncionais que agregam valor diretamente ao beneficiário da temática para qual o órgão foi criado;

- Bloco de macroprocessos de gestão e sustentação (5): macroprocessos de sustentação e apoio, utilizados para agregar valor para os processos de negócio e de governança;

- Bloco inferior horizontal (6) : refere-se à descentralização administrativa, prática comum na da Administração Direta, indica os macroprocessos supervisionados ou vinculados ao órgão central;

- Bloco superior horizontal (7): são dispostos botões indicativos (habilitados ou não) que vinculam a unidade organizacional do órgão representado nos processos. Por exemplo, ao representarmos o nível máximo de abstração do modelo de Cadeia de Valor (nível estratégico), o botão "Nome/Sigla do órgão", deverá estar habilitado no modelo, dessa maneira indicando a referida representação. Caso exista a necessidade de descompactar algum macroprocesso, o botão que deverá ser habilitado para aquele nível de abstração será o da "unidade organizacional" dona do referido processo de negócio e assim sucessivamente (nível 0 , nível 1 , nível 2, nível "N"). Observa-se que o limite de abstração para a descompactação da Cadeia de Valor, para esse modelo, deverá ser até o limite do fluxograma, que não entrará no escopo desse trabalho. Deve-se fazer a seguinte pergunta, antes de desdobrar para um outro nível de abstração: esse processo pode ser representado por meio de um fluxograma? Se a resposta for sim, finalizou a representação da Cadeia de Valor. Se a resposta for não, desdobra-se e representa-se outro nível de "macro-processo".

- Bloco de vinculação à estratégia do órgão (8): refere-se aos eixos e objetivos estratégicos: estabelecidos no mapa estratégico com prazos definidos para serem alcançados; a visão: fornece um ideal na direção da qual os esforços organizacionais possam se direcionar. 


\section{CONCLUSÕES E DISCUSSÕES}

Baseado nas informações da literatura e nas observações do estudo experimental, pode-se inferir que o elemento Cadeia de Valor tem sido um aliado importante e inovador no setor público, haja visto suas contribuições de identificação dos processos no auxílio das ações coordenadas de gestão por resultados, governança, dentre outras.

Esses resultados alavancam a necessidade desse estudo e da vinculação desse modelo, que de forma hipotética relaciona os conceitos. Ainda sobre o posicionamento superior e estendido, explica-se que foi elaborado com o objetivo de retratar (de forma visual) a incorporação da missão nos blocos de macroprocessos gerenciais, finalísticos e de suporte. A ideia implícita no desenho é da representação de um "guarda-chuva", ou seja, todos os processos do órgão funcionando "sob" "essa" missão. Complementando, assim, a visão do todo.

\section{AGRADECIMENTO}

Os autores agradecem o apoio das Agências brasileiras de pesquisa, desenvolvimento e inovação CNPq (INCT SegCiber), CAPES (FORTE e PROBRAL) e FAPDF (UIoT e SSDDC), bem como o suporte do Laboratório LATITUDE/UnB (SDN), e as cooperações com o Ministério da Economia (TED DIPLA 005/2016).

\section{REFERÊNCIAS}

Baldam, R. L. et al. Gerenciamento de processos de negócio - BPM: uma referência para implantação prática. Rio de Janeiro: Elsevier, 2014.

Gonçalves, J. E. L. As Empresas são grandes coleções de processos. São Paulo: RAE - Revista de Administração de Empresas, v40, n 1, p. 6-19, 2000.

Minayo, M. C. S. O desafio do conhecimento: pesquisa qualitativa em saúde. São Paulo: Ed. HUCITEC-ABRASCO, 1992. Porter, M, Vantagem Competitiva: Criando e sustentando um desempenho superior, Ed. Campus, 1990. 